\title{
Os usos sociais do desenho: pesquisa e projeto de tecnologia assistiva no contexto da APAE
} Social design uses: research and assistive technology
project in the context of APAE

Douglas Ladik Antunes ${ }^{1}$; Leonardo Silva Alves²; Carolina Souza Nunes'; Aline Nunes Kroth ${ }^{4}$; Álvaro Bruno Barioni ${ }^{5}$ 


\section{Resumo}

Este artigo apresenta os resultados parciais de pesquisa, de atividades que se iniciaram em 2010 e transcorrem até a atualidade. O tema central é o desenvolvimento de Tecnologias Assistivas na Associação de Pais e Amigos dos Excepcionais - APAE do município de São José - SC. O objetivo da pesquisa foi a realização de um estudo analítico do processo projetual e o aprimoramento das Tecnologias Assistivas (TA) priorizadas, relacionadas às atividades da vida diária, às condições de mobilidade e às atividades de apoio educacional. A metodologia deste projeto concentrou-se no processo cíclico, prático e participativo na criação de artefatos, através de modelos físicos e funcionais, com envolvimento direto dos profissionais da área da saúde, educação, design e das pessoas com deficiência. Concluiu-se a pertinência do processo contínuo de construção de modelos funcionais e verificou-se a possibilidade das seguintes abordagens de soluções: a) soluções pela simples gestão da informação interna à APAE-SJ; b) soluções em TA de apoio à mobilidade e apoio pedagógico que demandam baixo insumo tecnológico e financeiro; c) soluções que demandam maior insumo tecnológico e financeiro. Para tanto, ficou atestada a necessidade de um grupo de trabalho multidisciplinar permanente com foco em TA, bem como um espaço interno à APAE dedicado à construção de modelos físicos (laboratório oficina de criação).

Palavras-chave: Tecnologia Assistiva, Design, Pessoas com Deficiência, APAE, Modelos Físicos.

\section{Abstract}

This article presents the partial results of research, activities that began at 2010 until nowdays. The central theme is the development of Assistive Technologies in the Association of Parents and Friends of Exceptional Children - APAE in São José - SC. The aim was to carry out an analytical study of the design process and the improvement of Assistive Technology (AT) prioritized, related to activities of daily living, conditions of mobility and educational support activities. The methodology of this project focused on the cyclical, practical and participatory process in the creation of artifacts, through physical and functional models, with direct involvement of health professionals, education, design and people with disabilities. It was concluded the relevance of the ongoing process of building functional models and there was the possibility of the following approaches to solutions: a) solutions throught the simple management of internal information at APAE -SJ; b) TA's solutions to support mobility and teaching aids that require low technological and financial input; c) solutions that require greater technological and financial input. Therefore, it was attested the need for a permanent multidisciplinary working group focusing on TA, and an internal space to APAE dedicated to building physical models (laboratory workshop creation).

Keywords: Assistive Technology, Design, People with Disabilities, APAE, Physical Models

ISSN: $1808-3129$

\footnotetext{
${ }^{1}$ Douglas Ladik Antunes - douglasladik@hotmail.com - Professor Adjunto do Departamento de Design, do Centro de Artes, da Universidade do Estado de Santa Catarina - DDE/CEART/UDESC

Zeonardo Silva Alves - leonardosilvaalves@gmail.com - Bolsista de Extensão - Graduando em Bacharelado em Design Industrial do Departamento de Design, do Centro de Artes, da Universidade do Estado de Santa Catarina DDE/CEART/UDESC

${ }^{3}$ Carolina Souza Nunes - souzanunes.carol@gmail.com - Bolsista de Extensão - Graduanda em Bacharelado em Design Industrial do Departamento de Design, do Centro de Artes, da Universidade do Estado de Santa Catarina DDE/CEART/UDESC
}

${ }^{4}$ Aline Nunes Kroth - alinekroth@gmail.com - Bolsista Voluntária de Pesquisa Graduanda em Bacharelado em Design Industrial do Departamento de Design, do Centro de Artes, da Universidade do Estado de Santa Catarina - DDE/ CEART/UDESC

${ }^{5}$ Alvaro Bruno Barioni - alvarobruno.barioni@hotmail.com - Bolsista de Extensão - Graduando em Bacharelado em Design Industrial do Departamento de Design, do Centro de Artes, da Universidade do Estado de Santa Catarina - DDE/CEART/UDESC 


\section{INTRODUÇÃO}

As APAEs são instituições educacionais de caráter complementar à educação básica de ensino regular. Seu atendimento é focado nas pessoas com deficiência em diferentes níveis de comprometimento intelectual e motor. Por atender um universo muito amplo de deficiências, de variadas síndromes, com comprometimento intelectual e motor dos mais leves aos mais severos, as tecnologias assistivas de apoio às atividades são igualmente diversas, mais ou menos complexas conforme cada caso particular.

De maneira geral, no contexto das APAEs, as soluções de Tecnologias Assistivas e de Comunicação Alternativa são definidas por profissionais diretamente ligados ao processo educacional e terapêutico, como professores, fisioterapeutas e terapeutas ocupacionais. Muitas soluções, que visam dar autonomia às pessoas com deficiência são feitas à medida que as demandas são percebidas no auxílio à vida diária, na adequação postural, no auxílio à mobilidade, na comunicação aumentativa e alternativa, etc. Assim, tais soluções buscam cumprir funções práticas diretamente percebidas pela observação e são definidas de maneira experimental, com base nos conhecimentos técnicos de cada área, porém geralmente sem a contribuição de profissionais da área de projeto de produtos.

Em Tecnologia Assistiva (TA) cada solução é muito específica às particularidades da pessoa atendida, portanto não se pode afirmar um padrão de projeto, ou ainda uma gama de produtos que venham a atender todas as demandas percebidas. Em outras palavras, os projetos devem ser estritamente personalizados nas especificidades de cada deficiência, motora e/ou intelectual, que se manifestam de forma única em cada sujeito. Nesse contexto, o processo de projeto deve incorporar, como modelo funcional, as características morfológicas e dimensionais mais próximas da situação real: a forma do corpo, a postura, os padrões de espasticidade, a gestualidade, etc.

Um aspecto interno às APAEs é que os profissionais não são contratados especificamente para as soluções em TA, sendo este trabalho complementar às atividades dos educadores e profissionais da saúde. Não se questiona aqui a qualidade das soluções em projeto de TA nestes contextos educacionais, mas sim que este tipo de projeto tem caráter eminentemente interdisciplinar, e que, portanto, devem ser realizados por uma equipe com profissionais de variadas áreas de conhecimento.

O fato central é que designers não são contratados regularmente nestas instituições para este tipo de projeto, sendo estes profissionais de grande importância por sua habilitação tanto no processo de criação de artefatos, quanto no processo de modelamento dos materiais. A recomendação para que haja o envolvimento de projetistas se justifica pelo desenvolvimento analítico da forma (relacionada às soluções em TA) e do conteúdo, orientados aos requisitos pontuais de cada APAE.

Portanto, a problemática relacionada à pesquisa apresentada neste artigo visa responder não somente à adequação de soluções mais eficientes em TAs das pessoas com deficiência atendidas pela APAE-SJ, mas também a análise metodológica do processo de projeto relacionado a este contexto. 
O objetivo da pesquisa foi a realização de um estudo analítico do processo projetual e o aprimoramento das Tecnologias Assistivas priorizadas na Associação de Pais e Amigos dos Excepcionais - APAE do município de São José - SC. Como objetivos específicos buscou-se: a) elaboração de um diagnóstico de demandas por aprimoramento das TAs e definição de prioridades; b) projeto de TAs priorizadas e análise dos procedimentos metodológicos; c) verificação das condições de envolvimento dos profissionais e familiares dos educandos, bem como a apropriação de tais TAs no ambiente educacional e residencial.

\section{PROCEDIMENTOS DA PESQUISA}

Esta pesquisa inicialmente pode ser caracterizada como uma pesquisa qualitativa e exploratória ${ }^{1}$. Para Goldenberg (1999, p.49), "os dados da pesquisa qualitativa objetivam uma compreensão profunda de certos fenômenos sociais apoiados no pressuposto da maior relevância do aspecto subjetivo da ação social". Como existem motivações para a investigação direta e para o campo de ação, e claro, sua objetividade e não somente os aspectos da subjetividade, é perceptível um "alinhamento" desta pesquisa com a pesquisa-ação. Para Thiollent (2004, p.14):

a pesquisa-ação é um tipo de pesquisa social com base empírica que é concebida e realizada em estreita associação com uma ação ou com a resolução de um problema coletivo e no qual os pesquisadores e os participantes representativos da situação ou do problema estão envolvidos de modo cooperativo ou participativo

Este mesmo autor ainda insiste que deva existir a distinção entre os objetivos de pesquisa e os objetivos de ação, enfatizando três aspectos como resultado: a resolução de problemas, a tomada de consciência e a produção de conhecimento. Para ele, na pesquisa-ação "o objeto de investigação não é constituído pelas pessoas, e sim pela situação social e pelos problemas de diferentes naturezas encontrados nessa situação". Sendo assim, "a atitude do pesquisador é sempre uma atitude de 'escuta' e de elucidação dos vários aspectos da situação, sem imposição unilateral de suas concepções próprias." (THIOLLENT, 2004, p.16 e 17).

As definições acima postas pretendem esclarecer os procedimentos de trabalho desta pesquisa, que, embora busque resultados objetivos a serem materializados em novos projetos de objetos ou na readequação de objetos já criados, leva em conta os aspectos subjetivos da condição de criação de cada projeto² . Afinal, como afirma Minayo (2001), sobre a relação entre objetividade e subjetividade, em suas palavras, entre o "qualitativo" e o "quantitativo":

Não existe um "continuum" entre "qualitativo-quantitativo", em que o primeiro termo seria o lugar da "intuição", da "exploração" e do "subjetivismo"; e o se-

\footnotetext{
${ }^{1}$ Considera-se aqui o caráter exploratório da pesquisa por não haver a pré -existência de informações sistematizadas e análises desta temática no contexto em estudo.

${ }^{2}$ Cabe aqui lembrar que em contatos anteriores os bolsistas de extensão perceberam a tendência de uma educanda da APAE-SJ em piorar sua condição postural ao ver a fisioterapeuta da instituição. Isso foi compreendido como uma forma de obter maior atenção. É claro que tais aspectos adjacentes ao
}

processo projetual não devem ser entendidos como questões centrais a serem respondidas, mas sim como uma dimensão da problemática de pesquisa que deverá ser analisada a medida que se define o contexto de cada projeto. Espera-se que, semelhantemente a este caso citado, outros aspectos da subjetividade dos sujeitos atendidos devam emergir a partir do aprofundamento das relações de pesquisa. 
gundo representaria o espaço do científico, porque traduzido "objetivamente" e em "dados matemáticos".

A diferença entre qualitativo-quantitativo é de natureza. Enquanto cientistas sociais que trabalham com estatística apreendem dos fenômenos apenas a região "visível, ecológica, morfológica e concreta", a abordagem qualitativa aprofunda-se no mundo dos significados das ações e relações humanas, um lado não perceptível e não captável em equações, médias e estatísticas. (MINAYO, 2001, p. 22-23)

Portanto, tais apontamentos fundamentam tematicamente alguns dos princípios que foram atentados nesta pesquisa, em que, não basta ao processo de pesquisa focar simplesmente a criação de objetos como centrais, mas a referência anterior de compreender o processo de pesquisa como "integral", que deve abarcar essa correlação entre a objetividade e a subjetividade das relações entre sujeito e objeto de pesquisa. Não se pretende aqui esgotar esta discussão, porém esclarecer inicialmente esta perspectiva metodológica da observação e análise, e consequentemente melhor apresentar as referências epistemológicas desta pesquisa no campo do Design.

Embora se considere aqui a metodologia de pesquisa e de projeto relativamente distintas em alguns aspectos, e de natureza cíclica - em que não se pretende seguir uma lógica linearizada (etapa a etapa) e previamente rígida, pode-se, a título explicativo, apontar os seguintes procedimentos de pesquisa e desenvolvimento:

1. Levantamentos iniciais: levantamento preliminar de informações sobre a realidade observada. Assim, foram realizados os seguintes procedimentos:

\subsection{Levantamento e revisão bibliográfica;}

1.2 Entrevistas: realização de entrevistas com profissionais da APAE-SJ para levantamentos iniciais de informações sobre o contexto das TAs. Os profissionais entrevistados foram: fisioterapeutas, terapeutas ocupacionais e professores. O procedimento de entrevistas seguiu o modelo "bola de neve", em que os primeiros entrevistados selecionados, conforme determinados requisitos, indicaram um nome a ser entrevistado, buscando mapear e levantar informações com as pessoas mais envolvidas no processo atual de criação de TA no contexto estudado;

1.3 Diagnóstico preliminar: levantamento das demandas em suas categorias. Conforme sugere Bersch (2008), das principais TAs já desenvolvidas, ou de novas demandas a serem desenvolvidas por meio de projetos. Consideram-se aqui diferentes categorias de objetos, sendo eles: objetos criados (por profissionais) que merecem aprimoramentos em nível técnico e estético; tecnologias assistivas (produtos de mercado) que demandam por manutenção corretiva, manutenção preventiva e/ ou adaptação; novos objetos (TAs) para o apoio às atividades das pessoas com deficiência;

1.4 Priorização das demandas: debate colegiado para a priorização das TAs mais importantes;

1.5 Estabelecimento de metas. 
2. Desenvolvimento: Como sugerem Bonsiepe (1986) e Ripper \& Moreira (2004), a metodologia de design deve necessariamente contar com o envolvimento direto do projetista e do usuário na problematização e formulação dos objetivos de projeto, evitando assim a atividade projetual concentrada somente no detalhamento de projeto pré-elaborado. Neste sentido, este deve partir do pressuposto do levantamento de dados em campo, com professores, fisioterapeutas, terapeutas ocupacionais e educandos, e consequente modelamento físico / funcional concomitante ao processo criativo em pesquisa participativa colaborativa (GEILFUS, 1997).

Assim a metodologia projetual se aproximou ao proposto por Bomfim (1995) enquanto "método cíclico", caracterizado principalmente pela possibilidade de retorno entre as etapas de projeto, em que a avaliação negativa de determinada etapa sugere a revisão de etapas anteriores. Este método, acrescido pela adoção de modelos físicos intermediários de avaliação (Antunes \& Tonicelo, 2008), evitou o modelo de criação distanciada entre os projetistas e os usuários.

Considerando tal natureza cíclica da metodologia projetual, o processo projetual pode ser dividido basicamente em:

\subsection{Definições das situações específicas (problematização);}

2.2 Análises das situações específicas (análise do problema - observando as questões objetivas e subjetivas): com a elaboração de esquemas interpretativos (quadros sinóticos) que visaram facilitar o processo de análise e debate sobre as situações em estudo;

2.3 Análises de situações de similaridades e possibilidades de adaptações: com o cruzamento de informações sobre a realidade pesquisada e outras situações já levantadas, seja na etapa 1.1., seja por novas pesquisas pela internet. A pesquisa de tecnologias análogas tornou-se importante no sentido da apropriação de técnicas já validadas em campo, porém a serem consolidadas em seu desvio de função;

2.4 Experimentações: elaboração de modelos físicos para testes diretos na situação de uso dos objetos analisados. Esta etapa contou com a participação direta das pessoas com deficiência envolvidas na pesquisa, e previu um processo colaborativo de criação entre: projetistas - profissionais - pessoa com deficiência. Aqui foram utilizados como fundamento metodológico os procedimentos de trabalho observados no Laboratório de Investigações em Livre Desenho - LILD/PUC-Rio3;

\footnotetext{
${ }^{3}$ O LILD é um laboratório vinculado ao Programa de Pós Graduação em Artes e Design da Pontifícia Universidade Católica do Rio de Janeiro, que realizou diversos projetos de tecnologia assistiva junto ao Centro de Vida Independente - CVI nesta mesma universidade. O coordenador deste laboratório é o Prof. José Luiz Mendes Ripper, Livre Docente, que
}

foi orientador de doutoramento do presente coordenador deste projeto de pesquisa. Assim a metodologia de trabalho do LILD foi estudada na disciplina de Genealogia do Objeto Utilitário, na decorrência do doutoramento, e as relações de trabalho e pesquisa se estendem até a atualidade. 
2.5 Avaliações: avaliação sistemática dos modelos físicos desenvolvidos e escoIha dos modelos mais adequados a serem prototipados como produto final. Análise do processo metodológico (experimental) de definição de conceitos de projeto e de modelamento físico;

2.6 Implementação: com modelos físicos, modelos funcionais e protótipos executados no Laboratório Metal-Mecânico do Centro de Artes, da Universidade do Estado de Santa Catarina, contando com disponibilidade de um técnico em mecânica e a coordenação de um engenheiro mecânico (coordenador deste projeto). Tal laboratório reúne diversos equipamentos e máquinas operatrizes destinados ao processamento de diversos materiais, como metais, madeiras e materiais naturais, polímeros e compósitos. Embora os procedimentos de projeto se fundamentem centralmente nas metodologias de design de produto, não são ignoradas aqui as verificações estruturais apontadas por Shigley (2005) e Provenza (1996) para o dimensionamento e especificação de elementos de máquinas padronizados e não padronizados;

2.7 Análises de resultados: sendo subdividida em 1)Avaliação por observação direta: com uso de fotografia, filmagens e observação de uso das tecnologias assistivas de forma a verificar sua eficiência em todas as condições de uso; 2) avaliação por questionários e entrevistas;

2.8 Sistematização da experiência: elaboração de relatório parcial e final, artigo científico para publicação e materiais de divulgação, contendo os procedimentos de pesquisa, suas particularidades, os resultados finais e as análises pertinentes.

\section{PESQUISAS PRELIMINARES}

O objeto de estudo desta pesquisa surgiu a partir de uma demanda apontada por meio de contato entre a APAE-SJ e o presente coordenador de pesquisa ainda ao ano de 2010, em que diversos projetos foram desenvolvidos através da disciplina de Tópicos Especiais em Design Industrial. Entre estes projetos, cabe dar destaque às seguintes temáticas: pranchas adaptáveis a cadeiras de rodas (para atividades educacionais), adaptadores de lápis (engrossadores, adaptadores horizontais e verticais), adaptadores de tesoura (para corte auxiliado e para abertura automática da tesoura), alças duplas para copos, colher emborrachada, sistema adaptador de jogo de bocha para cadeirantes e prancha de comunicação alternativa adaptável à maca.

Desta forma, os projetos desenvolvidos a partir do enfoque em disciplina curricular foram implementados e seu uso, no decorrer dos últimos anos, demonstrou aspectos positivos e negativos em relação à sua funcionalidade. No ano de 2011, na mesma disciplina, porém com diferentes estudantes, os projetos de 2010 foram reavaliados e foi produzida uma tabela de verificações apontando aspectos a serem melhorados nos projetos. O quadro abaixo sintetizam os projetos avaliados (adaptado de MELLO; BARROS; ZANATTA, 2011): 


\section{Quadro 1: Avaliação e propostas de ajustes de projetos.}

\begin{tabular}{|c|c|c|c|c|}
\hline Nome & $\begin{array}{c}\text { Imagens } \\
\text { do Modelo }\end{array}$ & $\begin{array}{c}\text { Pontos } \\
\text { Positivos }\end{array}$ & $\begin{array}{c}\text { Pontos } \\
\text { Negativos }\end{array}$ & $\begin{array}{l}\text { Propostas } \\
\text { de Ajuste }\end{array}$ \\
\hline $\begin{array}{l}\text { Prancheta } \\
\text { para cadeira }\end{array}$ & & $\begin{array}{l}\text { Utilizada sempre } \\
\text { que necessário } \\
\text { e funciona quase } \\
\text { perfeitamente }\end{array}$ & $\begin{array}{l}\text { Precisa de ajus- } \\
\text { tes na fixação } \\
\text { para não ficar } \\
\text { bamba, algu- } \\
\text { mas fixações } \\
\text { caíram }\end{array}$ & $\begin{array}{l}\text { Refazer os } \\
\text { encaixes }\end{array}$ \\
\hline $\begin{array}{l}\text { Adaptador } \\
\text { para lápis }\end{array}$ & P & $\begin{array}{l}\text { Aceito pelos edu- } \\
\text { candos e funcio- } \\
\text { nou perfeitamen- } \\
\text { te }\end{array}$ & $\begin{array}{l}\text { A bola só cabe } \\
\text { em mãos gran- } \\
\text { des }\end{array}$ & $\begin{array}{l}\text { Construir mais } \\
\text { bolas em diver- } \\
\text { sos diâmetros }\end{array}$ \\
\hline $\begin{array}{l}\text { Adaptador } \\
\text { horizontal } \\
\text { para lápis }\end{array}$ & & $\begin{array}{l}\text { Aceito pelos } \\
\text { educandos } \\
\text { e está em uso }\end{array}$ & $\begin{array}{l}\text { Desgaste rápi- } \\
\text { do, cola do vel- } \\
\text { cro desprende- } \\
\text { se facilmente }\end{array}$ & $\begin{array}{l}\text { Construir para } \\
\text { diversas espes- } \\
\text { suras de lápis, } \\
\text { trocar o tipo de } \\
\text { cola utilizado no } \\
\text { velcro }\end{array}$ \\
\hline $\begin{array}{l}\text { Adaptador } \\
\text { de copo }\end{array}$ & & Funcionou bem & $\begin{array}{l}\text { Só funciona no } \\
\text { copo do protó- } \\
\text { tipo }\end{array}$ & $\begin{array}{l}\text { Construir adap- } \\
\text { tadores para di- } \\
\text { versos copos } \\
\text { (com velcro para } \\
\text { ajuste de alças) }\end{array}$ \\
\hline $\begin{array}{l}\text { Calha para } \\
\text { bocha }\end{array}$ & & $\begin{array}{l}\text { Funcionou, } \\
\text { porém por um } \\
\text { tempo muito li- } \\
\text { mitado }\end{array}$ & $\begin{array}{l}\text { Desgaste rápi- } \\
\text { do do material } \\
\text { como um todo }\end{array}$ & $\begin{array}{l}\text { Construir com } \\
\text { materiais mais } \\
\text { resistentes, tubo } \\
\text { de PVC de } 100\end{array}$ \\
\hline $\begin{array}{l}\text { Tesoura auto } \\
\text { tensionada } \\
\text { e tesoura } \\
\text { com uso au- } \\
\text { xiliar }\end{array}$ & & $\begin{array}{l}\text { Funcionou } \\
\text { perfeitamente }\end{array}$ & $\begin{array}{l}\text { Desgaste rápi- } \\
\text { do da tesoura }\end{array}$ & $\begin{array}{l}\text { Construir novas, } \\
\text { com tesouras } \\
\text { mais resistentes } \\
\text { e de fácil adapta- } \\
\text { ção } \\
\end{array}$ \\
\hline $\begin{array}{l}\text { Painel de } \\
\text { comunica- } \\
\text { ção alter- } \\
\text { nativa e au- } \\
\text { mentativa }\end{array}$ & & \begin{tabular}{|l} 
Funcionou e \\
é utilizado sem- \\
pre que possível
\end{tabular} & $\begin{array}{l}\text { Os professores } \\
\text { sentem pregui- } \\
\text { ça de montar } \\
\text { pois conexões } \\
\text { não são sim- } \\
\text { ples }\end{array}$ & $\begin{array}{l}\text { Necessária } \\
\text { maior área e de } \\
\text { mais possibilida- } \\
\text { des de encaixe } \\
\text { (cadeira e cama) }\end{array}$ \\
\hline
\end{tabular}




\begin{tabular}{|l|c|l|l|l|}
\hline \multicolumn{1}{|c|}{ Nome } & \multicolumn{1}{c|}{$\begin{array}{c}\text { Imagens } \\
\text { do Modelo }\end{array}$} & \multicolumn{1}{c|}{$\begin{array}{c}\text { Pontos } \\
\text { Positivos }\end{array}$} & \multicolumn{1}{c|}{$\begin{array}{c}\text { Pontos } \\
\text { Negativos }\end{array}$} & \multicolumn{1}{c|}{$\begin{array}{c}\text { Propostas } \\
\text { de Ajuste }\end{array}$} \\
\hline $\begin{array}{l}\text { Colher } \\
\text { emborra- } \\
\text { chada }\end{array}$ & $\begin{array}{l}\text { Não funcionou } \\
\text { bem }\end{array}$ & $\begin{array}{l}\text { O plástico não } \\
\text { protegia bem } \\
\text { o metal, sujava } \\
\text { fácil, difícil lim- } \\
\text { peza, não era } \\
\text { fácil a constru- } \\
\text { ção }\end{array}$ & $\begin{array}{l}\text { Substituir por } \\
\text { rachadas indus- } \\
\text { trializadas para } \\
\text { bebês }\end{array}$ \\
\hline
\end{tabular}

As demandas relacionadas acima não se justificam em seu desenvolvimento por si só, e sim nos benefícios que tais tecnologias assistivas podem proporcionar aos seus usuários, seja na maior independência das atividades da vida diária, no auxílio ao processo educacional ou ainda na valorização e melhoria da autoestima dos educandos. Neste sentido, o envolvimento das pessoas com deficiência no processo de projeto pode produzir efeitos positivos sobre esses sujeitos que a simples aplicação da TA desenvolvida não produziria. Enfim, entende-se aqui esta hipótese do benefício direto da TA na vida dessas pessoas, mas também do benefício de seu envolvimento no processo criativo.

Assim, longe de compreender o desenvolvimento deste tipo de projeto como uma prática altruísta, compreende-se aqui este tipo de projeto como fomentador de reflexões significativas à própria metodologia do design e da gestão do design no contexto da implementação de Tecnologia Assistiva. As particularidades desta categoria de projeto (específico à TA) podem estar relacionadas: à sua natureza interdisciplinar, ao projeto colaborativo, que abrangerá capacidades de comunicação diferenciadas entre as pessoas com deficiência e os projetistas, às práticas projetuais, com criação focada nas práticas experimentais de modelamento físico, aos conhecimentos sobre materiais e dispositivos mecânicos, resultantes do constante modelamento físico, às trocas de conhecimentos entre as diferentes áreas do conhecimento envolvidas.

\section{Uma breve revisão teórica}

O esboço desta revisão bibliográfica não pretende esgotar o tema, mas tão somente apontar as diretrizes teórico-temáticas que fundamentam uma possível epistemologia do design e uma prática de design, bem como tomar por referência a produção de significados a partir de determinados conceitos.

Inicialmente é interessante lançar luz sobre alguns conceitos já apontados anteriormente, por serem ponto pacífico de compreensão, mas que merecem o cuidado do esclarecimento. O principal deles situa a própria noção de Tecnologia Assistiva, que para Bersch (2008, p.2)

é um termo ainda novo, utilizado para identificar todo o arsenal de recursos e serviços que contribuem para proporcionar ou ampliar habilidades funcionais de pessoas com deficiência e consequentemente promover vida independente e inclusão. (...) A TA deve ser então entendida como um auxílio que promoverá a ampliação de uma habilidade funcional deficitária ou possibilitará a realização da 
função desejada e que se encontra impedida por circunstância de deficiência ou pelo envelhecimento.

Segundo a autora, o conceito de Tecnologia Assistiva surgiu de um profundo trabalho de revisão teórica do Comitê de Ajudas Técnicas - CAT, da Secretaria Especial dos Direitos Humanos da Presidência da República - SEDH/PR, tendo como foco a construção de políticas públicas brasileiras de fomento a este campo. Ela ainda afirma que para a comissão europeia que trata esse assunto, a ideia de tecnologia não inclui somente produtos, mas também contextos organizacionais e modos de agir que indicam uma série de princípios e componentes técnicos (BERSCH, 2008, p.2-3).

Desta forma, concordando com Bersch, entende-se que o conceito de Tecnologia Assistiva não busca fechar o tema em uma significação específica, mas sim de um ponto de partida conceitual que passa a definir diferentes possibilidades de noções operacionais em contextos específicos. Para o CAT a

Tecnologia Assistiva é uma área do conhecimento, de característica interdisciplinar, que engloba produtos, recursos, metodologias, estratégias, práticas e serviços que objetivam promover a funcionalidade, relacionada à atividade e participação, de pessoas com deficiência, incapacidades ou mobilidade reduzida, visando sua autonomia, independência, qualidade de vida e inclusão social (apud BERSCH, 2008, p.3-4)

A autora ainda esclarece que a TA pode ser compreendida como composta por categorias diferenciadas de acordo com os usos específicos na vida das pessoas com deficiência. Sua proposta de categorização faz menção às categorias definidas pela ISO 9999/2002, pelo Sistema Nacional de Classificação dos Recursos e Serviços de TA (EUA), pela Empowering Users Through Assistive Technology - EUSTAT (União Européia) e sua síntese surge de sua participação no Programa de Certificação em Aplicações da Tecnologia Assistiva - ATACP do College of Extended Learning and Center on Disabilities, da California State University de Northridge (BERSCH, 2008).

Assim, são postas por Bersch (2008) as seguintes categorias relacionadas à TA: 1. Auxílios para a vida diária e vida prática; 2. Comunicação aumentativa e alternativa; 3. Recursos de acessibilidade ao computador; 4. Sistemas de controle de ambiente; 5. Projetos arquitetônicos para acessibilidade; 6. Órteses e próteses; 7. Adequação postural; 8. Auxílios à mobilidade; 9. Auxílios para cegos e para pessoas com visão subnormal; 10. Auxílios para pessoas com surdez ou com déficit auditivo; 11. Adaptações em veículos. Como estas categorias visam à viabilização de políticas públicas suficientemente abrangentes no Brasil e no mundo, entende-se aqui que, por focar um contexto relativamente definido, nem todas as categorias de TA foram objeto dessa pesquisa.

Finalizando aqui as contribuições da autora, observa-se seu enfoque na condição interdisciplinar da temática relacionada à TA, quando enfatiza que

(...) dependendo da modalidade, agregará profissionais de distintas formações como os educadores, engenheiros, arquitetos, designers, terapeutas ocupacionais, fonoaudiólogos, fisioterapeutas, médicos, assistentes sociais, psicólogos, entre outros para o atendimento do usuário da TA.

(...) O serviço de TA atuará realizando a avaliação, prescrição e ensino da utilização de um recurso apropriado. Todo este processo deverá envolver diretamente o 
usuário e terá como base o conhecimento de seu contexto, a valorização de suas intenções e necessidades funcionais pessoais, bem como suas habilidades atuais. A equipe de profissionais contribuirá com o conhecimento sobre os recursos de TA disponíveis e indicados para cada caso, ou desenvolverá um novo projeto que possa atender uma necessidade particular do usuário em questão (BERSCH, 2008, p.10)

A natureza interdisciplinar reside também no campo do Design, entendendo aqui a continuidade existente entre o processo de projeto e o processo de pesquisa na área, na configuração de 'coisas' e na produção de conhecimento. Em outras palavras a interdisciplinaridade é intrínseca à epistemologia do design. Para Bomfim (1994, p.16)

(...) o design se diferencia de outros processos de configuração justamente pela fundamentação lógica que pretende, ou seja, o design é essencialmente uma práxis, mas ao contrário da arte e do artesanato, uma práxis que procura seguir princípios de diversas ciências na determinação da figura dos objetos.

Utilizando esta noção geral, ou melhor, esta conceituação de Bomfim, sem a pretensão de longa discussão acerca da 'natureza' do design, cabe a compreensão da produção teórica no campo do design como resultado da práxis, compreendo que esta deriva da produção a partir da ação concreta, da ação prática. E, da teoria marxista, a compreensão de práxis como resultado da ação prática e da ação reflexiva, da síntese entre teoria e prática. Em outras palavras, a construção epistemológica do campo do design a partir deste universo de pesquisa deve enaltecer a relação entre a ação política e ideológica do campo.

Deve-se aqui esclarecer o título da proposta associado à noção do "desenho social", que pode ser compreendido como a política social do processo de planejamento. Não se pretende aqui a construção da ideia de desenho em detrimento da ideia de design, mas sim a compreensão de desenho enquanto planejamento ou projeto. Embora as diferenciações conceituais tomadas aqui pareçam inócuas, é importante enfatizar a concordância com a proposta de Bonsiepe quando afirma que 'projeto' se refere à dimensão antropológica da criação e formação de artefatos materiais e simbólicos, enquanto 'design' significa um modo da atividade projetual do capitalismo tardio, tal como a partir dos anos 1970, difundiu-se globalmente (...) (BONSIEPE, 2011, p.13).

Deveras polêmica a afirmação de Bonsiepe, entende-se a importância de configuração da área de projeto a partir de ações práticas que produzem reflexões sobre a questão política deste campo por ser efetivamente científico. Considera-se a discussão terminológica como secundária. Assim, desloca-se aqui a discussão da produção econômica (e de acumulação de capital) a partir da atividade de projeto, colocando o foco na valorização dos sujeitos sociais, na melhoria da qualidade de vida e nas potencialidades educacionais do campo - de formação profissional e de formação da cidadania. 


\section{Resultados e discussões finais}

A pesquisa no contexto da APAE-SJ demonstra claramente a grande demanda que o universo das APAEs apresentam em relação ao desenvolvimento de projetos de produtos por designers, que foquem as Tecnologias Assistivas na perspectiva do campo do design. Atualmente tais projetos, em grande monta, são desenvolvidos por profissionais da área da saúde e professores, que chegam em alternativas satisfatórias do ponto de vista prático-funcional, porém que necessitam de maiores aprofundamentos em termos da diversidade de alternativas, de maior eficiência e durabilidade, de melhor relação estético-funcional.

O desenvolvimento de soluções em projetos de Tecnologias Assistivas no contexto da APAE-SJ vem reafirmando algumas hipóteses inicialmente previstas: primeiramente sobre o caráter interdisciplinar das propostas, em que realmente observouse fundamental o envolvimento dos profissionais da área da saúde, particularmente fisioterapeutas e terapeutas ocupacionais, e também dos profissionais envolvidos nas atividades da vida diária dos educandos, sendo estes principalmente os professores.

Todas as soluções desenvolvidas (que serão apontadas mais adiante) tiveram o envolvimento dos profissionais citados acima nas etapas de geração de alternativas e testes com os modelos físicos intermediários. Após redefinição dos modelos físicos, foram criados os protótipos (em ambiente de oficina), que por sua vez tornaram-se diretamente o "produto final", visto que as soluções são estritamente individualizadas e não requerem a produção seriada. É de suma importância destacar que dois profissionais da APAE-SJ frequentaram a oficina do CEART nas etapas de montagem dos modelos físicos e montagem dos produtos finais, e esta participação direta viabilizou a criação de tais soluções com mais praticidade e suporte técnico sob o olhar da área da saúde.

Pode-se afirmar parcialmente verdadeira a primeira hipótese assumida no projeto de pesquisa original, de que: "As prioridades de melhorias de TAs na APAE-SJ se relacionam aos casos de maior comprometimento motor e na categoria de auxílio à vida diária, particularmente nas atividades relacionadas à educação", pois verificouse que a categoria de TA mais demandada foi a de "adequação postural" e não diretamente das atividades relacionadas à educação especificamente.

Em relação à segunda hipótese do projeto original, afirmada como sendo: "O projeto de TAs na APAE-SJ é caracterizado por particularidades do processo projetual muito relacionado ao processo participativo interdisciplinar de diagnóstico, análise contextual, modelamento físico e definições de soluções finais"; verificou-se que as principais particularidades do processo participativo se relacionaram a:

1. Participação direta dos educadores e profissionais da área de saúde no apontamento de demandas relacionadas à mobilidade, adequação postural, educação e terapia (nesta ordem de importância);

2. Participação direta dos educandos nas etapas de desenvolvimento de modelos físicos intermediários, no desenvolvimento dos produtos finais e seus respectivos testes de funcionalidade;

3. Participação direta dos profissionais na montagem dos modelos e produtos finais, principalmente nos acabamentos finais, como estofamento e impermeabilização; 
4. Participação direta dos profissionais na avaliação dos produtos finais e implementação;

5. Capacitação técnica dos profissionais: determinadas soluções técnicas definidas eram de domínio somente dos "projetistas" envolvidos (coordenador e bolsistas) como aquelas geradas a partir de compensados curvados e adaptadores de apoio de cabeça feitos em aço. Porém, tais "domínios específicos" serão repassados na forma de conteúdos em futuros cursos de capacitação aos profissionais da APAE-SJ.

Em relação à última hipótese do projeto original, cabe aqui lembrar que : "A apropriação de TAs no ambiente residencial dos educandos, mesmo que relacionadas às atividades educacionais, pode ocorrer mediante o envolvimento de familiares na pesquisa sobre as TAs". Ressalta-se que não foi possível verificar esta hipótese, visto que, para tal verificação seria necessário um bolsista com tempo de dedicação em campo mais relacionado à pesquisa que ao desenvolvimento de soluções técnicas (como vem sendo feito por bolsistas de extensão).

Como a presente pesquisa não foi contemplada com bolsa de iniciação científica (como solicitado no projeto original), as atividades priorizadas se concentraram no contexto exclusivo do local da APAE-SJ, não se estendendo à residência dos educandos. Parte-se aqui do pressuposto que tal pesquisa complementar é de fundamental importância, porém, só poderá ser executada com o envolvimento direto de um bolsita de iniciação científica, visto que este tipo de pesquisa requer o aprofundamento de observações relacionadas ao campo da pesquisa qualitativa, para a compreensão de aspectos sociais, econômicos, educacionais e culturais das famílias dos educandos da APAE-SJ, o campo de projeto das tecnologias assistivas e sua implementação.

Verificou-se no decorrer da pesquisa que a metodologia inicialmente proposta é adequada, porém, como afirmado, a não aprovação de uma bolsa de IC prejudicou o acompanhamento na APAE-SJ e sua extensão ao domicílio dos educandos. As etapas iniciais que envolveram do diagnóstico inicial, à priorização e o estabelecimento de metas de projeto respeitaram o cronograma proposto. Porém, com o andamento dos trabalhos de modelamento e experimentação, verificou-se a necessidade de maior tempo devido à ampliação de novas demandas e à concentração dos trabalhos entre o coordenador e dois bolsistas de extensão.

Verificou-se que as TAs trabalhadas na APAE-SJ sugerem três abordagens de soluções distintas que envolvem não somente o processo de projeto, mas também o processo de gestão das TAs. Assim, destas três linhas de abordagem, pode-se destacar as seguintes conclusões particulares:

a) Alcance de soluções pela simples gestão da informação: percebe-se que determinadas TAs são implementadas pela simples gestão da informação na APAE-SJ. Para tanto, faz-se necessário o estabelecimento de uma rotina de reuniões e discussões sobre o tema Tecnologia Assistiva. No caso da APAE-SJ, verificou-se que a demanda por determinadas TAs em salas de aula específicas eram supridas pelo simples transporte da respectiva TA de uma sala para outra. Neste caso, o fato da pesquisa através da UDESC propor reuniões regulares na APAE promoveu a troca de informaÇões e a solução automática de situações de demandas por TAs em salas específicas;

b) Soluções que demandam baixo insumo tecnológico: percebeu-se que em muitas situações de projetos relacionados principalmente à adequação postural é 
possível o uso de materiais acessíveis e de baixo custo, que demandam para seu beneficiamento somente algumas máquinas e ferramentas manuais. É o caso dos apoios de cabeça e apoios de pés que podem ser executados em compensado (naval), com ou sem curvatura aplicadas em moldes de baixa complexidade. Nestes casos, muitas soluções demandadas nas APAEs poderiam ser resolvidas por um departamento interno, uma oficina de Tecnologia Assistiva. Para tanto, com a prorrogação deste projeto, pretende-se o apoio institucional para a montagem de uma oficina "piloto" na APAE-SJ;

c) Soluções que demandam maior insumo tecnológico: algumas situações específicas demonstraram a necessidade de apoio de instituições externas à APAE, pela demanda de mão de obra especializada para a execução, como no caso de soldagem e usinagem de peças específicas. Há também situações em que é necessária uma série de tecnologias diversificadas para medição e modelamento físico de objetos, como é o caso dos adaptadores de assento e adaptadores posturais que busquem maior ajustamento ergonômico, durabilidade e melhor relação estético-funcional. Neste caso, ressalta-se aqui a importância de continuidade de investigação sobre o "sistema de ajuste de postura a vácuo" em que se debruça a pesquisa atualmente.

Enfim, evidencia-se que o contexto de soluções em TAs nas APAEs apresenta uma proposta de implementação estruturada nesses três eixos de ação: formação do grupo de estudos e discussões sobre Tecnologia Assistiva dentro da APAE, formação do laboratório ou oficina de Tecnologia Assistiva dentro da APAE, e o estabelecimento de parcerias com grupos especializados externos à APAE. Este último, demonstra a importância de se desenvolver na UDESC um espaço com atendimento especializado ao contexto das APAEs, que pode viabilizar o uso dos laboratórios e oficinas já existentes como apoio às demandas de TAs das APAEs e, circunstancialmente, nas escolas regulares, visto que atualmente tornou-se lei a inclusão de pessoas com deficiência no ensino regular. No entanto, é imprescindível que haja um local especializado para este tipo de trabalho na UDESC, principalmente se realizado a partir da lógica do projeto (Design).

Entre os projetos demandados, trabalhados neste projeto de pesquisa, ou ainda em vias de encaminhamento, destacam-se os seguintes:

Quadro 2: Levantamento de demandas.

\begin{tabular}{|l|l|l|l|}
\hline \multicolumn{1}{|c|}{ T.A. } & \multicolumn{1}{|c|}{ Categoria } & Quem apontou & \multicolumn{1}{|c|}{$\begin{array}{c}\text { Educandos } \\
\text { atendidos }\end{array}$} \\
\hline Jogos diversos & $\begin{array}{l}\text { Material de apoio } \\
\text { pedagógico }\end{array}$ & Prof. Tiago & $\begin{array}{l}\text { Semi-estruturada } \\
\text { (turma) }\end{array}$ \\
\hline $\begin{array}{l}\text { Pranchas adapta- } \\
\text { das }\end{array}$ & $\begin{array}{l}\text { Material de apoio } \\
\text { pedagógico }\end{array}$ & $\begin{array}{l}\text { Profs. Fátima, Cé- } \\
\text { sar, Sonia, Vinicius, } \\
\text { Alessandra, Van- } \\
\text { derléia }\end{array}$ & $\begin{array}{l}\text { Maria Alice, Camila } \\
\text { e Luana }\end{array}$ \\
\hline Apoio de pés & $\begin{array}{l}\text { Adequação postu- } \\
\text { ral }\end{array}$ & $\begin{array}{l}\text { Profs Vinicius, So- } \\
\text { nia, Fátima e César }\end{array}$ & $\begin{array}{l}\text { Maria Alice, Camila } \\
\text { e Luana }\end{array}$ \\
\hline
\end{tabular}




\begin{tabular}{|c|c|c|c|}
\hline T.A. & Categoria & Quem apontou & $\begin{array}{l}\text { Educandos } \\
\text { atendidos }\end{array}$ \\
\hline Prancha & $\begin{array}{l}\text { Material de apoio } \\
\text { pedagógico }\end{array}$ & $\begin{array}{l}\text { Profs Arlete, Marco } \\
\text { e Vanessa }\end{array}$ & Paulo \\
\hline $\begin{array}{l}\text { Cadeira com apoio } \\
\text { de braço }\end{array}$ & $\begin{array}{l}\text { Adequação postu- } \\
\text { ral }\end{array}$ & Prof. Vanessa & Ronaldo \\
\hline $\begin{array}{l}\text { Apoio de pé regu- } \\
\text { lável }\end{array}$ & $\begin{array}{l}\text { Adequação postu- } \\
\text { ral }\end{array}$ & Prof. Joice & Educação precoce \\
\hline $\begin{array}{l}\text { Estrutura de apoio } \\
\text { (encosto e assento) }\end{array}$ & $\begin{array}{l}\text { Adequação postu- } \\
\text { ral }\end{array}$ & $\begin{array}{l}\text { Profs. Alessandra e } \\
\text { Vanderleia }\end{array}$ & Luana \\
\hline Cinto (tipo polvo) & $\begin{array}{l}\text { Adequação postu- } \\
\text { ral }\end{array}$ & Fisio. Marco & Paulo \\
\hline $\begin{array}{l}\text { Cadeira com apoio } \\
\text { de braço + cinto }\end{array}$ & $\begin{array}{l}\text { Adequação postu- } \\
\text { ral }\end{array}$ & $\begin{array}{l}\text { Profs. Vagner, Laia- } \\
\text { ra e Andreia }\end{array}$ & José Luis \\
\hline Barra paralela & $\begin{array}{l}\text { Atividade de apoio } \\
\text { à fisioterapia }\end{array}$ & Fisio. Fabiana & diversos \\
\hline $\begin{array}{l}\text { Apoio do ombro e } \\
\text { cabeça }\end{array}$ & $\begin{array}{l}\text { Adequação postu- } \\
\text { ral }\end{array}$ & $\begin{array}{l}\text { Profs. Arlete, Marco } \\
\text { e Vanessa }\end{array}$ & $\begin{array}{ll}\text { Paulo e Márcio } \\
\text { Luana }\end{array}$ \\
\hline $\begin{array}{l}\text { Cadeira de rodas } \\
\text { larga }\end{array}$ & Mobilidade & $\begin{array}{l}\text { Profs. Arlete, Marco } \\
\text { e Vanessa }\end{array}$ & Márcio \\
\hline Abdutor Móvel & $\begin{array}{l}\text { Adequação postu- } \\
\text { ral }\end{array}$ & Prof. Joice & Educação precoce \\
\hline $\begin{array}{l}\text { Adaptadores de lá- } \\
\text { pis }\end{array}$ & $\begin{array}{l}\text { Material de apoio } \\
\text { pedagógico }\end{array}$ & Prof. Roberta & Luana \\
\hline
\end{tabular}

Entre tais demandas apontadas, não foi necessário o uso de ferramentas de priorização por pontuação, conforme previsto no projeto de pesquisa original, pois os projetos priorizados foram aqueles em que os educandos atendidos têm maior comprometimento motor. Entre eles foram priorizados: o apoio de cabeça para Luana, sua adequação postural, além das barras paralelas da sala de fisioterapia e os apoios para pés. Destes, já estão implementados: 3 apoios de cabeças (para diferentes pessoas), 4 apoios de pés - para educandos que tendem a entrar em padrões gestuais pela falta de apoio frontal dos pés, os adaptadores de pranchas ( 2 adaptadores - de pranchas de alimentação para pranchas de atividades educacionais), 2 apoios de pés móveis para as salas de educação precoce, uma prancha de equilíbrio para a fisioterapia. Entre as demandas não atendidas plenamente até o momento, destacam-se a finalização do modelamento do assento e encosto, baseado no sistema a vácuo de modelamento, e o ajustamento das barras paralelas na sala de fisioterapia.

Vale ressaltar que a pesquisa se demonstrou satisfatória no desenvolvimento de produtos que são executados a partir de tecnologias e materiais de baixo custo. Porém, por se considerar esta pesquisa inacabada, não é possível no momento apontar maiores resultados sobre a montagem da oficina de TA na APAE-SJ, bem como sobre a apropriação de tais tecnologias pelos professores e demais profissionais desta instituição. 


\section{REFERÊNCIAS BIBLIOGRÁFICAS}

ANTUNES, D.L.; TONICELO, R.H.S. Tecnologias Produtivas, Design e Pesquisa Participativa - Estudo de Caso do Artesanato de Cipó Imbé em Garuva - SC. São Paulo: 8아 P\&D Design, 2008.

BERSCH, Rita. Introdução à Tecnologia Assistiva. Centro Especializado em Desenvolvimento Infantil - CEDI. Porto Alegre-RS, 2008.

BOMFIM, Gustavo A. Metodologia para Desenvolvimento de Projetos. João Pessoa: Ed. Universitária UFPB, 1995.

Sobre a Possibilidade de uma Teoria do Design. Estudos em Design. V.2, n. 2. Rio de Janeiro: Associação de Ensino do Design no Brasil, 1994.

BONSIEPE, Gui. Design, Cultura e Sociedade. São Paulo: Blucher, 2011.

GEILFUS, F. 80 Herramientas para el Desarollo Participativo: diagnóstico, planificación, monitoreo, evaluación. IICA. GTZ. San Salvador- El Salvador, 1997.

GOLDENBERG, Mirian. A Arte de Pesquisar: Como Fazer Pesquisa Qualitativa em Ciências Sociais. Rio de Janeiro: Ed. Record, 1999.

MELLO, Caio; BARROS, Ivandro de; ZANATTA, Thiago. Trabalho Final: Tópicos Especiais em Design Industrial 3. Bacharelado em Design Industrial - CEART/UDESC. Florianópolis-SC, 2011.

MINAYO, Maria Cecília de Souza (org.). Pesquisa Social. Teoria, método e criatividade. $18^{\underline{a}}$ ed. Petrópolis: Vozes, 2001.

PROVENZA, Francesco. Projetista de Máquinas. São Paulo: Ed. F. Provenza, 1996.

RIPPER, J. L.M.; MOREIRA, L.E. Métodos de Ensino de Design de Produtos e sua Aplicação às Estruturas da Engenharia Civil. Brasília: COBENGE, 2004.

SIGLEY, J.; MISCHKE, C.R.; BUDYNAS, R.G. Projeto de Engenharia Mecânica. 7’ạ ed. Porto Alegre : Bookman, 2005.

THIOLLENT, Michel. A Metodologia da Pesquisa-ação. 13a ed. São Paulo: Cortez, 2004. 